(Journal of Civil Engineering, Building and Transportation)

Available online http://ojs.uma.ac.id/index.php/jcebt

\title{
Prediksi Penurunan Konsolidasi Menggunakan Preloading dan Prefabricated Vertical Drain dengan Software Metode Elemen Hingga
}

\section{Prediction of Consolidation Settlement Using Preloading and Prefabricated Vertical Drain with Finite Element Method Software}

\author{
Tika Ermita Wulandari \\ Program Studi Teknik Sipil, Fakultas Teknik \\ Universitas Medan Area, Indonesia \\ *Corresponding Email: tikaermitawulandari@gmail.com
}

\section{Abstrak}

Konsolidasi merupakan proses keluarnya air dari dalam pori-pori tanah yang menyebabkan terjadinya perubahan volume tanah yang berdampak rusaknya konstruksi diatasnya. Hal ini lebih fatal jika penurunan yang terjadi bersifat setempat. Dewasa ini penggunaan vertical drain semakin banyak diminati terutama dengan sistem Prefabricated Vertical Drain (PVD) yang dapat mengurangi waktu proses konsolidasi tanah secara signifikan dari beberapa tahun ke hitungan bulan serta dengan kemajuan teknologi terciptalah software yang dapat mempermudah dalam menghitung pengerjaan konstruksi dengan program komputer, salah satunya software metode elemen hingga (Plaxis) untuk menghitung proses penurunan konsolidasi. Penelitian ini bertujuan menganalisis menggunakan software Metode Elemen Hingga dengan bantuan program plaxis 2D dan 3D untuk mendapatkan besar penurunan konsolidasi. Hasil dari pemodelan 2D dan 3D akan dibandingkan sehingga didapat hasil yang paling mendekati dengan kondisi lapangan. Dari hasil analisis dapat disimpulan besar penurunan pada Plaxis 3D lebih mendekati dengan data settlement plate S29 dengan besar penurunan 6,956m atau selisih $-0,234 \mathrm{~m}$, sedangkan besar penurunan pada Plaxis 2D yaitu 7,491 dengan selisih penurunan sebesar 0,301m.

Kata Kunci: Konsolidasi, Preloading, Prefabricated Vertical Drain, Plaxis

\begin{abstract}
Consolidation is the process of removing water from the pores of the soil which causes changes in the volume of the soil which results in damage to the construction above it. This is more fatal if the decline that occurs is local. Nowadays the use of vertical drains is increasingly in demand, especially with the Prefabricated Vertical Drain (PVD) system which can reduce the time of the soil consolidation process significantly from several years to a matter of months and with technological advances, software is created that can make it easier to calculate construction work with computer programs, one of which is the only finite element method software (Plaxis) to calculate the consolidation settlement process. This study aims to analyze using Finite Element Method software with the help of $2 D$ and $3 D$ plaxis programs to get the consolidation settlement size. The results of $2 D$ and $3 D$ modeling will be compared so that the results that are closest to the field conditions are obtained. From the results of the analysis, it can be concluded that the magnitude of the decrease in Plaxis 3D is closer to the settlement plate data S29 with a decrease of $6.956 m$ or a difference of $-0.234 m$, while the magnitude of the decrease in Plaxis $2 D$ is 7.491 with a difference of decrease of $0.301 \mathrm{~m}$.
\end{abstract}

Keywords: Consolidation, Preloading, Prefabricated Vertical Drain, Plaxis

How to Cite: Wulandari, T. E. (2021). Prediksi Penurunan Konsolidasi Menggunakan Preloading dan Prefabricated Vertical Drain dengan Software Metode Elemen Hingga. JCEBT (Journal of Civil Engineering, Building and Transportation). 5 (2): 99 - 108 


\section{PENDAHULUAN}

Tanah didefinisikan sebagai material yang terdiri dari agregat (butiran) mineralmineral padat yang tidak tersementasi (terikat secara kimia) satu sama lain dan dari bahan-bahan organik yang telah melapuk (yang berpartikel padat) disertai dengan zat cair dan gas yang mengisi ruang-ruang kosong di antara partikelpartikel padat tersebut (Mochtar \& Mochtar, 1995).

Untuk mendirikan bangunan, baik gedung, jembatan, jalan raya, pelabuhan, semuanya membutuhkan pondasi yang kuat. Agar diperoleh pondasi yang kuat, pondasi tersebut haruslah terletak pada tanah yang mampu menahan beban pondasi. Pada kenyataannya tanah yang ditemukan di lapangan tidak semuanya baik menerima beban. Misalnya pada tanah lunak, tidak mampu menerima beban, sehingga tanah lunak tersebut perlu diperbaiki agar dapat membangun pondasi (Ahmad, 2014).

Pada kenyataanya tanah lunak bersifat kurang menguntungkan secara teknis untuk mendukung suatu pekerjaan konstruksi. Plastisitas yang tinggi, kembang susut yang tinggi dan daya dukung yang rendah serta kandungan air yang tinggi dan sulit terdrainasi karena permeabilitas tanah relatif rendah serta kompresibilitas yang besar menyebabkan tanah mengalami penurunan yang besar dan dalam waktu yang sangat lama. Hal ini seringkali menjadi kendala dalam pelaksanaan suatu pekerjaan konstruksi (Hidayati \& Ardana, 2008).

Konsolidasi (consolidation) adalah suatu proses pengecilan volume secara perlahan-lahan pada tanah jenuh sempurna dengan permeabilitas rendah akibat pengaliran sebagian air pori. Dengan kata lain, pengertian konsolidasi adalah proses terperasnya air tanah akibat bekerjanya beban statis, yang terjadi sebagai fungsi waktu karena kecilnya permeabilitas tanah. Proses ini berlangsung terus sampai kelebihan tekanan air pori yang disebabkan oleh kenaikan tegangan total telah benar-benar hilang (Darwin, 2018).

Dampak yang terjadi konstruksi akan rusak karena adanya penurunan tanah yang terjadi. Hal ini lebih fatal jika penurunan yang terjadi bersifat setempat (Hayati, 2019).

Dewasa ini penggunaan vertical drain semakin banyak diminati terutama dengan sistem Prefabricated Vertical Drain 
(PVD) yang dapat mengurangi waktu proses konsolidasi tanah secara signifikan dari beberapa tahun ke hitungan bulan saja (Ariza, dkk., 2014).

Seiring dengan kemajuan teknologi terciptalah berbagai macam metode dan software yang dapat mempermudah dalam menghitung pengerjaan konstruksi dengan program komputer, salah satunya software metode elemen hingga (Plaxis) untuk menghitung proses penurunan konsolidasi.

Berdasarkan uraian yang telah dijelaskan sebelumnya maka dapat dirumuskan masalah yang akan diteliti dan dianalisis yaitu bagaimana prediksi penurunan konsolidasi dengan bantuan software Metode Elemen Hingga yaitu Plaxis 2D dan 3D.

Penelitian ini bertujuan menganalisis menggunakan software Metode Elemen Hingga dengan bantuan program plaxis 2D dan 3D untuk mendapatkan besar penurunan konsolidasi. Hasil dari pemodelan 2D dan 3D akan dibandingkan sehingga didapat hasil yang paling mendekati kondisi lapangan. Adapun manfaat yang ingin dicapai untuk memambah wawasan bagi penulis dan pembaca tentang aplikasi penggunaan software Plaxis dalam mempercepat perhitungan konsolidasi dan kombinasi preloading dengan Prefabricated Vertical Drain (PVD) mampu memperpecat proses konsolidasi.

\section{METODE PENELITIAN}

Proyek reklamasi Belawan phase 1 dengan luas $\pm 350 \mathrm{~m} \times 362 \mathrm{~m}$, proyek ini dikerjakan bertujuan untuk penambahan lahan/daratan yang nantinya akan digunakan untuk Dermaga, Container Yard dan Utilitas TPK Belawan. Peta lokasi proyek dapat dilihat pada Gambar 1.

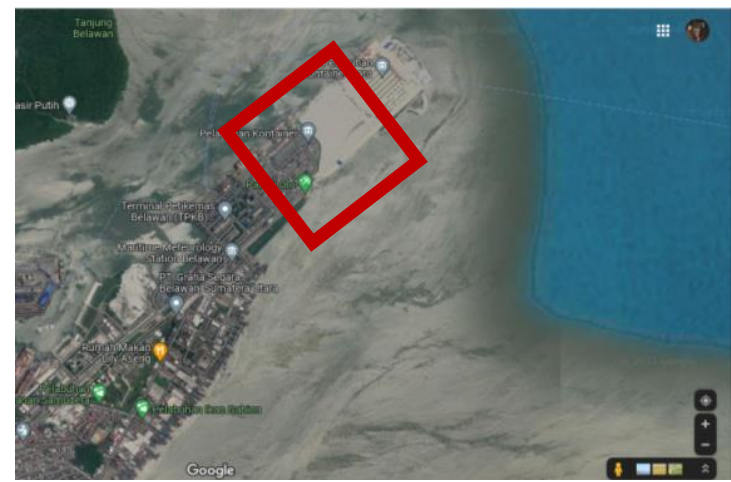

Gambar 1. Lokasi reklamasi Belawan phase 1 Sumber : Google Maps, 2021

Penelitian ini menganalisis kondisi tanah eksisting berdasarkan data Bore Hole tanah yaitu data BH-01 yang mewakili kondisi tanah disekitarnya. Lokasi BH-01 dapat dilihat pada Gambar 2. 


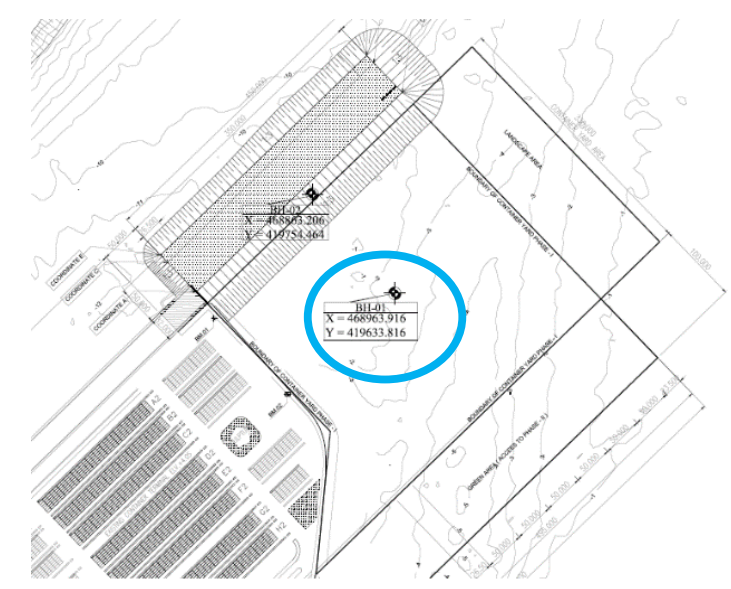

Gambar 2. Lokasi BH-01

Sumber : Data Proyek, 2016

Lokasi titik bore yang ditinjau berdekatan dengan titik settlement plate 29 (S29), Sehingga data yang akan digunakan sebagai data pembanding adalah penurunan pada S29. Denah lokasi S29 dapat dilihat pada Gambar 3.

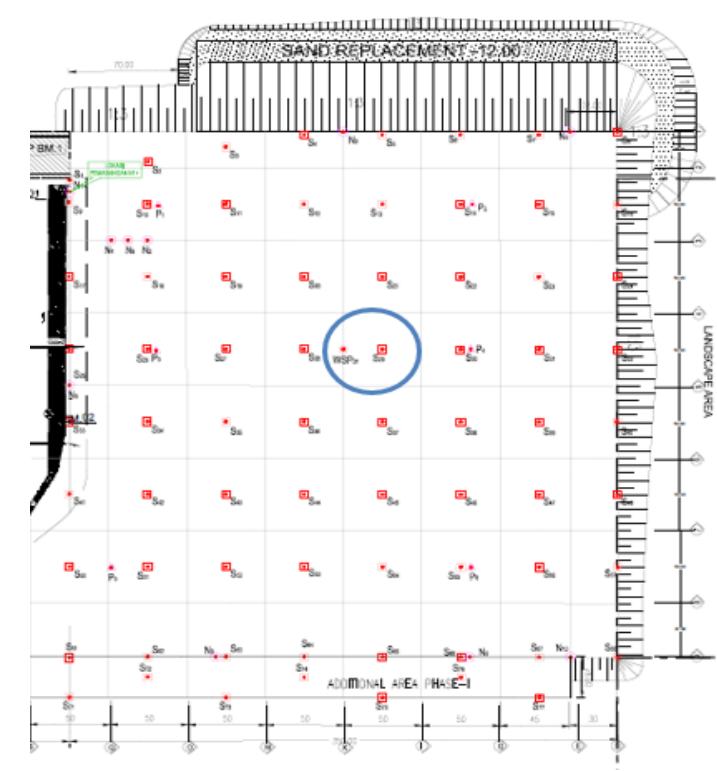

Gambar 3. Denah Lokasi S29

Sumber : wulandari, 2020
Dari hasil pengujian tanah dilapangan sedalam $60 \mathrm{~m}$ didapatlah data sebagai berikut :

1. Jenis tanah pada kedalaman $0-1,5 m$ adalah sandy clay

2. Jenis tanah pada kedalaman 1,5-15m adalah clay

3. Jenis tanah pada kedalaman 15-18m adalah sandy silt

4. Jenis tanah pada kedalaman 18-22m adalah organic clay

5. Jenis tanah pada kedalaman 22-32m adalah clayey sand

6. Jenis tanah pada kedalaman $32-37 \mathrm{~m}$ adalah silty clay

7. Jenis tanah pada kedalaman 37-50m adalah clayey sand

8. Jenis tanah pada kedalaman 50-60m adalah silty clay

Pada pelaksanaannya di Lapangan proyek reklamasi ini menggunakan metode kombinasi preloading dan PVD. Kombinasi metode ini diharapkan akan mempercepat waktu konsolidasi timbunan agar pekerjaan konstruksi diatasnya dapat dilakukan. Penurunan konsolidasi di lapangan dapat dipantau dengan menggunakan instrumen geoteknik berupa settlement plate (Manihuruk \& Iskandar, 2019). Instalasi PVD dilakukan pada kedalaman $-40 \mathrm{~m}$ sampai dengan $+4 \mathrm{~m}$ 
diatas permukaan tanah. Proses instalasi PVD dapat dilihat pada Gambar 4.

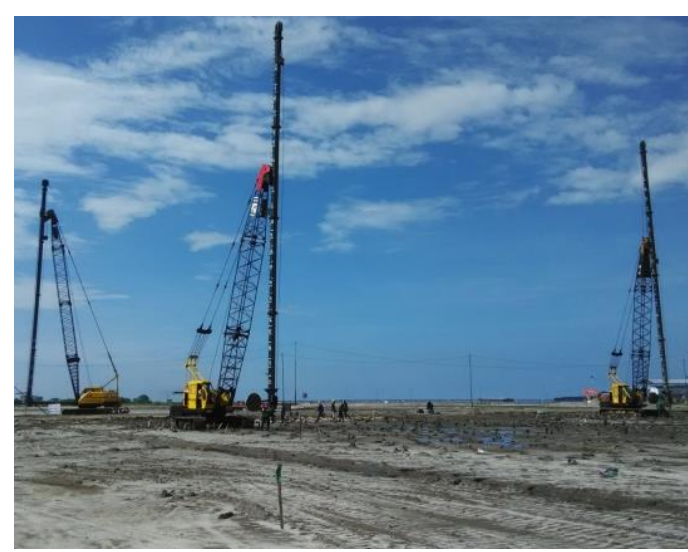

Gambar 4. Instalasi PVD

Sumber : Dokumentasi Proyek, 2016

Pemodelan pada Plaxis dilakukan dengan memperhitungkan efek smear zone output plaxis persis dengan yang terjadi di Lapangan. Sementara pemodelan PVD menggunakan ekuivalen yang awalnya setempat-setempat diubah menjadi plane strain. Tanah dibagi menjadi 2 prilaku tanah yaitu drained dan undrained. Lapisan tanah yang memiliki data pengujian konsolidasi dimodelkan soft soil sedangkan lapisan tanah yang tidak dilakukan pengujian konsolidasi dimodelkan mohr-coulomb dengan korelasi nilai NSPT. Data-data yang diinput pada program Plaxis dapat dilihat pada Tabel 1.

pada tanah agar hasil yang didapat dari

Tabel 1. Hasil analisis pemodelan tanah dengan korelasi nilai NSPT

\begin{tabular}{|c|c|c|c|c|c|c|c|c|c|c|}
\hline \multirow{2}{*}{ Uraian } & \multirow{2}{*}{ Satuan } & \multicolumn{9}{|c|}{ Material Properties Bore Hole-01 } \\
\hline & & Timbunan & $\begin{array}{c}\text { Sandy } \\
\text { Clay }\end{array}$ & Clay & $\begin{array}{c}\text { Sandy } \\
\text { Silt }\end{array}$ & $\begin{array}{c}\text { Organic } \\
\text { Clay }\end{array}$ & $\begin{array}{l}\text { Clayey } \\
\text { Sand } 1\end{array}$ & Silty Clay 1 & $\begin{array}{l}\text { Clayey } \\
\text { Sand } 2\end{array}$ & Silty Clay 2 \\
\hline Nama Lapisan & \multicolumn{2}{|c|}{ Preloading } & 1 & 2 & 3 & 4 & 5 & 6 & 7 & 8 \\
\hline $\begin{array}{c}\text { Material } \\
\text { model }\end{array}$ & - & $\begin{array}{c}\text { Mohr- } \\
\text { Coulomb }\end{array}$ & $\begin{array}{c}\text { Mohr- } \\
\text { Coulomb }\end{array}$ & $\begin{array}{c}\text { Mohr- } \\
\text { Coulomb }\end{array}$ & $\begin{array}{c}\text { Mohr- } \\
\text { Coulomb }\end{array}$ & $\begin{array}{c}\text { Mohr- } \\
\text { Coulomb }\end{array}$ & $\begin{array}{c}\text { Mohr- } \\
\text { Coulomb }\end{array}$ & $\begin{array}{c}\text { Mohr- } \\
\text { Coulomb }\end{array}$ & $\begin{array}{c}\text { Mohr- } \\
\text { Coulomb }\end{array}$ & $\begin{array}{c}\text { Mohr- } \\
\text { Coulomb }\end{array}$ \\
\hline Kedalaman & $\mathrm{m}$ & $11.0-0$ & $0-1,5$ & $1,5-15$ & $15-18$ & $18-22$ & $22-32$ & $32-37$ & $37-50$ & $50-60$ \\
\hline Drainage type & - & Drained & Drained & Undrained & Drained & Undrained & Drained & Undrained & Drained & Undrained \\
\hline $\mathrm{E}$ & $\mathrm{kN} / \mathrm{m}^{2}$ & 25000 & 600 & 600 & 600 & 600 & 600 & 600 & 700 & 700 \\
\hline$\gamma_{-}$unsat & $\mathrm{kN} / \mathrm{m}^{3}$ & 14,84 & 7,85 & 7,85 & 7,85 & 2,2 & 13,9 & 8,9 & 13,9 & 8,9 \\
\hline$\gamma_{-}$sat & $\mathrm{kN} / \mathrm{m}^{3}$ & 19,1 & 14,6 & 14,6 & 14,6 & 10,3 & 18,4 & 15,1 & 18,4 & 15,1 \\
\hline$\lambda^{*}$ (lambda) & & - & - & 0,1019 & - & 0,2272 & - & - & 0,0692 & - \\
\hline$\kappa^{*}$ (kappa) & & - & - & 0,0394 & - & 0,0449 & - & - & 0,0269 & - \\
\hline$v(n u)$ & & 0,3 & 0.35 & 0.35 & 0,35 & 0,35 & 0,35 & 0,35 & 0,35 & 0,35 \\
\hline c_ref & $\mathrm{kN} / \mathrm{m}^{2}$ & 0 & 15,5 & 15,5 & 15,5 & 12,9 & 22,4 & 29,2 & 22,4 & 29,2 \\
\hline$\varphi(\mathrm{phi})$ & $\circ$ & 33,1 & 12,4 & 12,4 & 12,4 & 20,8 & 14,1 & 13,3 & 14,1 & 13,3 \\
\hline $\mathrm{k} \_\mathrm{x}$ & $\mathrm{m} / \mathrm{hari}$ & 1 & 0,0005 & 0,0005 & 0,0005 & 0,2182 & 0,0153 & 0,0005 & 0,0153 & 0,0005 \\
\hline k_y & $\mathrm{m} /$ hari & 1 & 0,0005 & 0,0005 & 0,0005 & 0,2182 & 0,0153 & 0,0005 & 0,0153 & 0,0005 \\
\hline
\end{tabular}

Sumber : Analisis Peneliti, 2020 
Adapun perbedaan pemodelan 2D dan 3D yaitu untuk tebal mesh 2D diasumsikan tidak terbatas sedangkan pada 3D tergantung pada jumlah baris PVD yang akan dimodelkan. Pemodelan smear zone untuk 2D disumsikan berbentuk silinder dengan s' kelipatan dari dm (ekivalensi diameter mandrel) sedangkan 3D menggunakan ukuran s' yang sebenenya terjadi di Lapangan. Untuk pemodelan 2D menggunakan rw (jari-jari PVD ) dengan nilai setengah dari nilai Ekivalensi Diameter PVD $\left(\mathrm{d}_{\mathrm{w}}\right), \mathrm{r}_{\mathrm{s}}$ (radius smear zone) dan $\mathrm{r}_{\mathrm{e}}$ (radius ekivalen pengaruh PVD) sedangkan Pemodelan 3D digunakan ukuran smear zone, pola instal dan daerah pengaruh yang sebenarnya. Untuk 2D deformasi yang terjadi kearah vertikal dan horizontal sedangkan 3D berdeformasi arah lateral, vertikal dan horizontal.

\section{HASIL DAN PEMBAHASAN}

Pada permodelan Plaxis dibutuhkan analisis dampak dari efek instalasi PVD sehingga dilakukan perhitungan efek smear zone dengan menggunakan metode hird. Lapisan-lapisan yang berdampak saat instalasi PVD dapat diuraikan pada Tabel 2.
Tabel 2. Lapisan yang terdampak efek smear zone

\begin{tabular}{|c|c|c|c|}
\hline Lapisan & Area & Jenis Tanah & $\begin{array}{c}\text { Tebal } \\
\text { lapisan } \\
(\mathrm{m})\end{array}$ \\
\hline 1 & $\begin{array}{c}\text { Reklamasi } \\
\text { Tahap 2 }\end{array}$ & Sand & 1,2 \\
\hline 2 & $\begin{array}{c}\text { Reklamasi } \\
\text { Tahap 1 }\end{array}$ & Sand & 2,8 \\
\hline 3 & Eksisting & sandy clay & 1,5 \\
\hline 4 & Eksisting & Clay & 13,5 \\
\hline 5 & Eksisting & Sandy Silt & 3 \\
\hline 6 & Eksisting & Organic Clay & 4 \\
\hline 7 & Eksisting & Clayey Sand & 10 \\
\hline 8 & Eksisting & Silty Clay & 5 \\
\hline 9 & Eksisting & Clayey Sand & 3 \\
\hline
\end{tabular}

Sumber : Analisis Peneliti, 2020

\section{Perhitungan Efek Smear Zone}

Dari data properties tanah yang terganggu akibat pemancangan PVD (smear zone), besar nilai $\mathrm{k}_{\mathrm{ax}}$ (permeabilitas arah horizontal) akibat pemancangan PVD dapat dihitung dengan menggunakan persamaan hird sebagai berikut:

$\frac{k_{h p}}{k_{a x}}=\frac{2 B^{2}}{3 R^{2}\left[\ln \left(\frac{R}{r_{s}}\right)+\left(\frac{k_{a x}}{k_{s}}\right) \ln \left(\frac{r_{s}}{r_{w}}\right)-\frac{3}{4}\right]}$

$\mathrm{k}_{\mathrm{ax}} \quad$ : koefisien permeabilitas horizontal kondisi tanah tidak terganggu

$\mathrm{k}_{\mathrm{s}} \quad$ : koefisien permeabilitas horizontal kondisi tanah terganggu kondisi axysimmetric

B : $1 / 2$ dari lebar

R : Jari jari ekivalen 
Rs : radius smear zone

Rw : radius PVD

Tabel 3. Nilai Kax sebelum dan sesudah smear zone

\begin{tabular}{|c|c|c|c|}
\hline Uraian & Satuan & $\begin{array}{c}\mathrm{K}_{\mathrm{ax}} \\
\text { sebelum } \\
\text { efek smear } \\
\text { zone } \\
\end{array}$ & $\begin{array}{c}\mathrm{K}_{\mathrm{ax}} \text { sebelum } \\
\text { efek smear } \\
\text { zone }\end{array}$ \\
\hline Timbunan & $\mathrm{m} /$ hari & 1 & 1 \\
\hline sandy clay & $\mathrm{m} /$ hari & 0,0005 & 0,0001 \\
\hline Clay & $\mathrm{m} /$ hari & 0,0005 & 0,0001 \\
\hline Sandy Silt & $\mathrm{m} /$ hari & 0,0005 & 0,0001 \\
\hline Organic Clay & $\mathrm{m} / \mathrm{hari}$ & 0,2182 & 0,0387 \\
\hline Clayey Sand 1 & $\mathrm{~m} /$ hari & 0,0153 & 0,0027 \\
\hline Silty Clay 1 & $\mathrm{~m} / \mathrm{hari}$ & 0,0005 & 0,0001 \\
\hline Clayey Sand 2 & $\mathrm{~m} /$ hari & 0,0153 & 0,0027 \\
\hline Silty Clay 2 & $\mathrm{~m} /$ hari & 0,0005 & 0,0001 \\
\hline
\end{tabular}

Sumber : Analisis Peneliti, 2020

\section{Perhitungan Software Plaxis}

Pemodelan Plaxis mengikuti cross section S29, dimana lokasi yang ditinjau berada pada koordinat $\quad X=468963,916$ LS dan Y $=419633,816$ LU. Cross section S29 dapat dilihat pada Gambar 5.

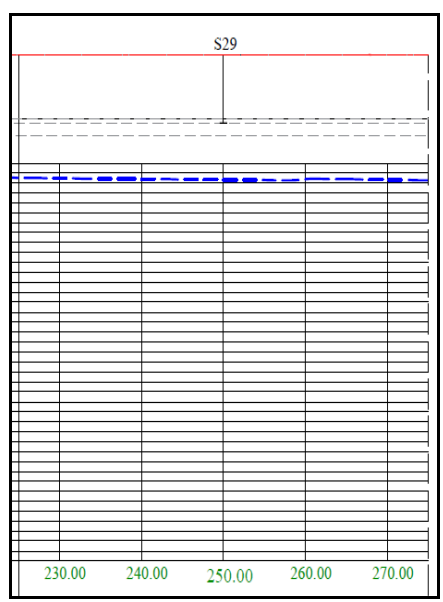

Gambar 5. Cross section S29

Sumber : Dokumentasi Proyek, 2016
Kondisi lapangan disimulasikan sedetail mungkin ke dalam program Plaxis untuk mengimplementasikan tahapan pelaksanaan sehingga hasil yang didapat akurat dan menggambarkan kondisi yang sebenarnya di Lapangan. Jenis pemodelan yang digunakan yaitu plane strain dengan Lebar penampang yang ditinjau 50m. Tipe mesh very fine dengan 15 titik nodal. Pemodelan lapisan tanah dan PVD dengan Plaxis 2D dapat terlihat pada Gambar 6.

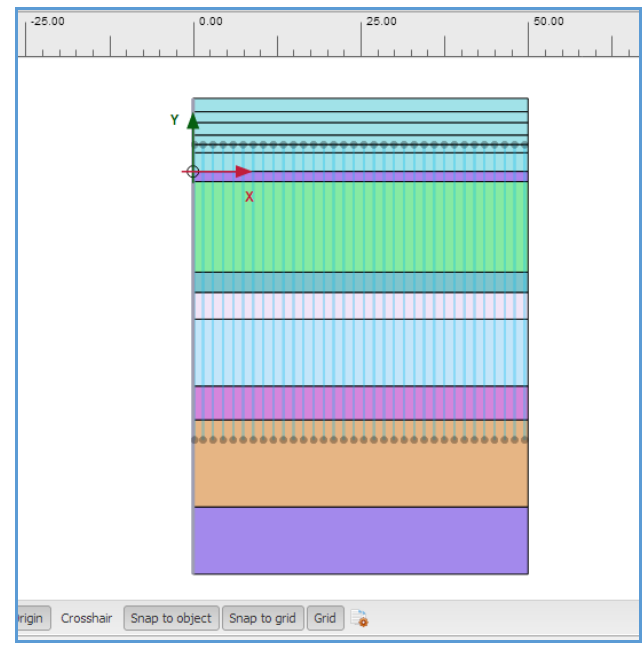

Gambar 6. Pemodelan Plaxis 2D Sumber : Analisis Peneliti, 2020

Pada Plaxis 3D pemodelan lapisan tanah mengunakan pemodelan full, 10 titik nodal dan lebar penampang tinjauan $50 \mathrm{~m}$. Pemodelan PVD dua baris berjarak 1,5m menggunakan pola pemasangan segitiga. Pemodelan PVD 3D dapat dilihat pada Gambar 7. 


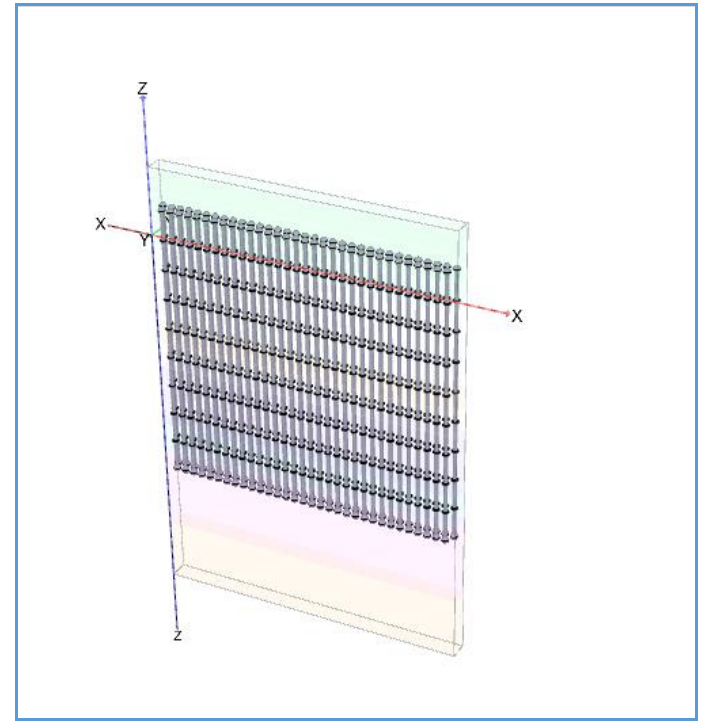

Gambar 7. Pemodelan PVD dengan Plaxis 3D Sumber : Analisis Peneliti, 2020

Penentuan titik tinjau pada Generate Mesh berada pada koordinat $\mathrm{x}=25 \mathrm{~m} \mathrm{y}=0$. Dimana hasil yang didapat dengan menggunkaan tipe mesh very fine untuk
Plaxis 2D yaitu 11.279 elemen dan 90.711 node sedangkan pada Plaxis 3D 114.620 elemen dan 156.555 node.

Dengan karekteristik smear zone $\mathrm{s}=2$ $\mathrm{k}=2$, diperoleh hasil penurunan yang terjadi pada Plaxis 2D sebesar 7,491m, Plaxis 3D sebesar $6,956 \mathrm{~m}$ sedangkan total penurunan konsolidasi pada data settlement plate S-29 sebesar 7,190m. Hal ini dapat didapat dikatakan bahwa penurunan 3D lebih mendekati dengan selisih penurunan sebesar -0,234m, sedangkan 2D selisih penurunan sebesar 0,301m. Hasil output Plaxis dapat dilihat pada Tabel 4 .

Tabel 4. Hasil output Plaxis

\begin{tabular}{|c|c|c|c|c|c|c|c|c|c|c|c|c|c|c|}
\hline \multicolumn{6}{|c|}{ Plaxis 2D } & \multicolumn{9}{|c|}{ Plaxis 3D } \\
\hline Point & $\begin{array}{l}\text { Time } \\
\text { [day] }\end{array}$ & $\begin{array}{c}\mathrm{u} \_\mathrm{y}[\mathrm{m}] \\
\mathrm{N} / \mathrm{A}\end{array}$ & Point & $\begin{array}{l}\text { Time } \\
\text { [day] }\end{array}$ & $\begin{array}{l}\mathrm{u}_{-\mathrm{y}} \\
{[\mathrm{m}]} \\
\mathrm{N} / \mathrm{A}\end{array}$ & Point & $\begin{array}{l}\text { Time } \\
\text { [day] }\end{array}$ & $\mathrm{u} \_\mathrm{z}[\mathrm{m}]$ & Point & $\begin{array}{l}\text { Time } \\
\text { [day] }\end{array}$ & $\begin{array}{c}\mathrm{u} \_\mathrm{z} \\
{[\mathrm{m}]}\end{array}$ & Point & $\begin{array}{l}\text { Time } \\
\text { [day] }\end{array}$ & $\mathrm{u}_{-} \mathrm{z}[\mathrm{m}]$ \\
\hline 0 & - & - & 16 & 120,00 & $-4,120$ & 0 & 0,00 & - & 16 & 3,01 & $-0,073$ & 32 & 65,24 & $-2,104$ \\
\hline 1 & - & 0,000 & 17 & 123,99 & $-4,471$ & 1 & 0,00 & 0,000 & 17 & 3,02 & $-0,073$ & 33 & 91,50 & $-2,520$ \\
\hline 2 & 1,50 & $-0,036$ & 18 & 130,00 & $-5,049$ & 2 & 0,00 & 0,000 & 18 & 3,03 & $-0,073$ & 34 & 103,00 & $-2,695$ \\
\hline 3 & 3,00 & $-0,073$ & 19 & 131,00 & $-5,371$ & 3 & 0,01 & 0,000 & 19 & 3,06 & $-0,074$ & 35 & 109,57 & $-2,978$ \\
\hline 4 & 4,50 & $-0,100$ & 20 & 132,00 & $-5,756$ & 4 & 0,01 & 0,000 & 20 & 3,11 & $-0,075$ & 36 & 118,07 & $-3,426$ \\
\hline 5 & 6,00 & $-0,129$ & 21 & 135,99 & $-6,127$ & 5 & 0,03 & $-0,001$ & 21 & 3,22 & $-0,077$ & 37 & 120,00 & $-3,531$ \\
\hline 6 & 8,00 & $-0,944$ & 22 & 143,97 & $-6,497$ & 6 & 0,06 & $-0,001$ & 22 & 3,44 & $-0,081$ & 38 & 125,00 & $-3,884$ \\
\hline 7 & 11,99 & $-1,274$ & 23 & 159,94 & $-6,899$ & 7 & 0,12 & $-0,003$ & 23 & 3,88 & $-0,089$ & 39 & 130,00 & $-4,271$ \\
\hline 8 & 16,00 & $-1,444$ & 24 & 191,87 & $-7,267$ & 8 & 0,24 & $-0,005$ & 24 & 4,75 & $-0,105$ & 40 & 131,00 & $-4,480$ \\
\hline 9 & 19,99 & $-1,588$ & 25 & 235,00 & $-7,491$ & 9 & 0,48 & $-0,011$ & 25 & 6,00 & $-0,129$ & 41 & 132,00 & $-4,739$ \\
\hline 10 & 27,97 & $-1,815$ & & & & 10 & 0,96 & $-0,022$ & 26 & 11,00 & $-0,799$ & 42 & 138,57 & $-5,227$ \\
\hline 11 & 43,94 & $-2,160$ & & & & 11 & 1,92 & $-0,045$ & 27 & 16,00 & $-1,043$ & 43 & 151,70 & $-5,725$ \\
\hline 12 & 75,87 & $-2,689$ & & & & 12 & 3,00 & $-0,073$ & 28 & 19,28 & $-1,161$ & 44 & 177,96 & $-6,301$ \\
\hline 13 & 103,00 & $-3,085$ & & & & 13 & 3,00 & $-0,073$ & 29 & 25,85 & $-1,339$ & 45 & 229,46 & $-6,898$ \\
\hline 14 & 106,99 & $-3,287$ & & & & 14 & 3,01 & $-0,073$ & 30 & 38,98 & $-1,623$ & 46 & 235,00 & $-6,956$ \\
\hline 15 & 114,97 & $-3,785$ & & & & 15 & 3,01 & $-0,073$ & 31 & 52,11 & $-1,874$ & & & \\
\hline
\end{tabular}


Dari hasil grafik output Plaxis yang meskipun elevasi timbunan belum diperoleh menunjukkan terdapat bertambah sedangkan pada Plaxis perbedaan pola penurunan pemodelan dilakukan pembagian fase kalkulasi Plaxis dengan data settlement plate S29. didasarkan atas kenaikan tinggi timbunan. Perbedaan ini disebabkan peninjauan data Hal ini dapat dilihat pada Gambar 8. pada Lapangan dilakukan setiap hari

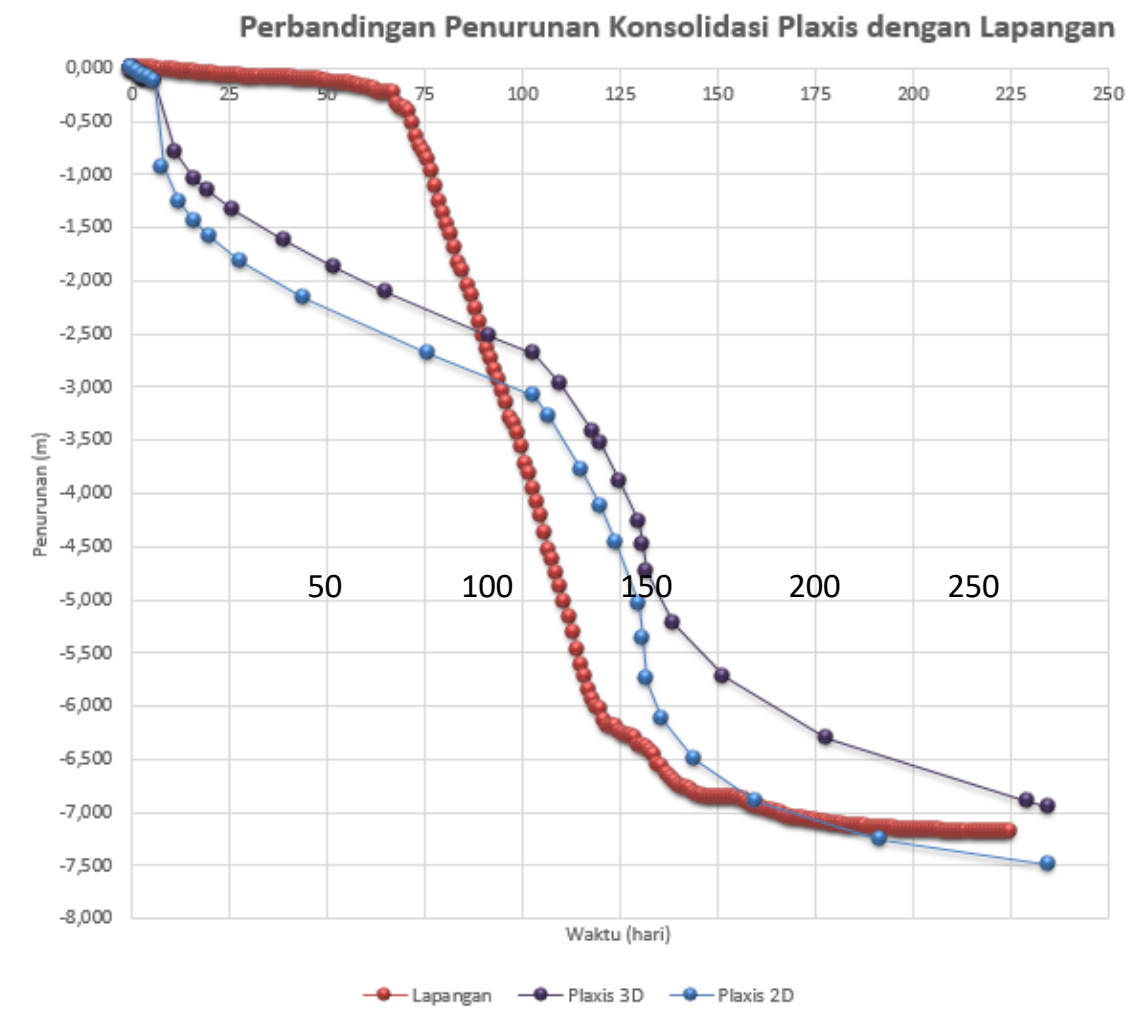

Gambar 8. Perbandingan penurunan konsolidasi Sumber : Analisis Peneliti, 2020

\section{KESIMPULAN}

Dari hasil analisis menggunakan software Metode Elemen Hingga yaitu Plaxis maka dapat disimpulan besar penurunan pada Plaxis 3D lebih mendekati dengan data settlement plate S29 dengan besar penurunan $6,956 \mathrm{~m}$ atau selisih $-0,234 \mathrm{~m}$, sedangkan besar penurunan pada Plaxis 2D yaitu 7,491 dengan selisih penurunan sebesar $0,301 \mathrm{~m}$.

\section{DAFTAR PUSTAKA}

Ahmad, I. (2014) Analisa Metode Perbaikkan Tanah Lunak dan Kohesif : Jurnal Menara Jurusan Teknik Sipil FT. UNJ ISSN : $1907-4360$.

Ariza, Satibi, S. \& Fatnanta, F. (2014). Analisis Pengaruh Parameter Permeabilitas 
Smear Zone Terhadap Penurunan Konsolidasi (Studi Kasus Di Pltu \pm Pekanbaru, Riau). Jom FTEKNIK Volume 1 No. 2 Oktober 2014.

Darwis, H. (2018). Dasar-dasar Mekanika Tanah. Yogyakarta : Pena Indis.

Das, B.M. (2010). Principles of Geotechnical Engineering, Cengage Learning. tamford, Connecticut.

Hayati, T. (2019). Analisis Pengaruh Smear Zone pada Penurunan dan Waktu Konsolidasi Proyek Reklamasi Belawan Fase II dengan Plaxis 2D dan 3D.

Hidayati, A.M \& Ardana, M.D.W. (2008). Kombinasi Preloading Dan Penggunaan Pre-Fabricated Vertical Drains untuk Mempercepat Konsolidasi Tanah Lempung Lunak (Studi Kasus Tanah Lempung Suwung Kangin). Jurnal Ilmiah Teknik Sipil vol. 12 No. 12, Juli 2008.

Hird, C. C., Pyrah, I. C., Russell, D., \& Cinicioglu, F. (1995). Modelling the effect of vertical drains in two-dimensional finite element analyses of embankments on soft ground. Canadian Geotechnical Journal, 32(5), 795-807.

Iskandar, R. (2018). Teknik Perbaikan Tanah dengan Menggunakan PVD dan Preloading. Medan : USU Press.

Manihuruk, J.N. \& Iskandar, R. (2019) (Evaluasi Derajat Konsolidasi Preloading dan Prefabricated Vertical Drain (PVD) dengan Menggunakan Metode Asaoka (Studi Kasus Proyek Container Port Phase 2 Pelabuhan Belawan).

Mochtar, N.E \&. Mochtar, I.B (1995). Mekanika Tanah (Prinsip-prinsip Rekayasa Geoteknis) Braja M. Das. Jakarta : Penerbit Erlangga.

Wulandari, T. E. (2020). Analisis Konsolidasi menggunakan Preloading dan Prefabricated Vertical Drain dengan Metode Perhitungan Analitis, Plaxis 2D dan 3D pada Proyek Reklamasi Belawan Phase I. Tesis. Sekolah Pascasarjana USU. 